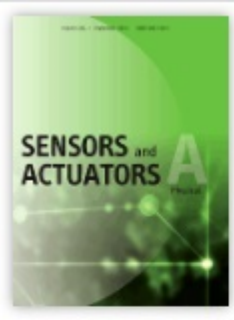

ISSN: 0924-4247

\section{Submit Your Paper}

\section{Supports Open Access}

View Articles

\section{Guide for Authors}

\section{$\checkmark$}

Abstracting/ Indexing

Track Your Paper

$\checkmark$

Order Journal

\section{Journal Metrics \\ > CiteScore: $\mathbf{2 . 7 9}$ (1) \\ Impact Factor: 2.311 (i) \\ 5-Year Impact Factor: $\mathbf{2 . 5 3 8}$ (1) \\ Source Normalized Impact per Paper \\ (SNIP): 1.363 (i) \\ SCImago Journal Rank(SJR): 0.699 \\ (1) \\ $>$ View More on Journal Insights \\ Your Research Data \\ $>$ Share your research data \\ $>$ Visualize your data \\ > Data in Brief co-submission \\ > MethodsX co-submission
Related Links
$>$ Author Stats (1)
$>$ Researcher Academy
$>$ Author Services
$>$ Try out personalized alert features

\section{Sensors and Actuators A: Physical}

An international journal devoted to research and development of physical transducers

Editor in Chief: Paddy French, Liang Dong

$>$ View Editorial Board

Sensors and Actuators A: Physical brings together multidisciplinary interests in one journal entirely devoted to disseminating information on all aspects of research and development of solid-state devices for transducing physical signals. Sensors and Actuators A: Physical regularly publishes original...

Read more

\section{Most Downloaded Recent Articles Most Cited Open Access Articles}

Graphene and its sensor-based applications: A review Anindya Nag | Arkadeep Mitra | ... Energy harvesting during human walking to power a wireless sensor node Yang Kuang | Tingwen Ruan | ...

Room-temperature gas sensing of $\mathrm{ZnO}$-based gas sensor: A review Ling Zhu | Wen Zeng

$>$ View All Most Downloaded Articles

\section{Announcements}

Heliyon Partner Journal

This journal has partnered with Heliyon, an open access journal from Elsevier publishing quality peer reviewed research across all disciplines. Heliyon's team of experts provides editorial excellence, fast publication, and high visibility for your paper. Authors can quickly and easily transfer their research from a Partner Journal to Heliyon without the need to edit, reformat or resubmit.

$>$ Learn more at Heliyon.com

$>$ View All

\section{Mendeley Data}

The latest Mendeley datasets for Sensors and Actuators A: Physical.

Data for: Flexible piezoelectric liquid volume sensor

Seungbum Hong | Yong-Hwa Park | ...

1 file $(2018)$

Data for: Effect of Piezoelectric Layer Thickness and Poling Conditions on the Performance of Cantilever Piezoelectric Energy Harvesters on Ni Foils Hong Goo Yeo | Susan Trolier-McKinstry

12 files (2018)

$>$ View All 


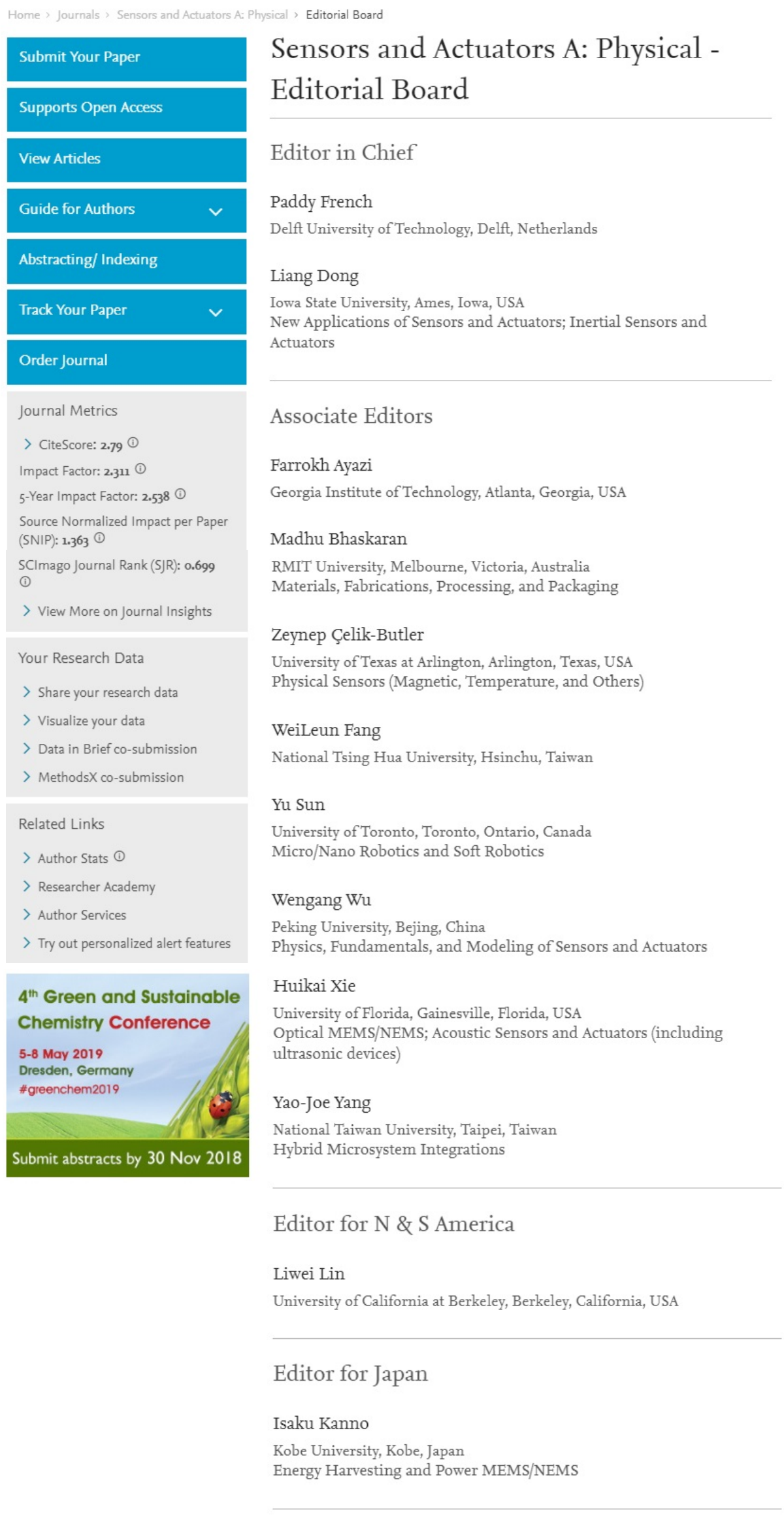


Editors for Micromechanics Section

Victor Bright

University of Colorado, Boulder, Colorado, USA

\section{WeiLeun Fang}

National Tsing Hua University, Hsinchu, Taiwan

Qiao Lin

Columbia University, New York, New York, USA

Mitsuhiro Shikida

Hiroshima City University, Hiroshima, Japan

\section{Founding Editor}

Simon Middelhoek

Delft, Netherlands

Editorial Advisory Board

\section{Wolfgang Benecke}

Bremen, Germany

Siebe Bouwstra

Amsterdam, Netherlands

Hiroyuki Fujita

Meguro-Ku, Japan

Yogesh Gianchandani

Ann Arbor, Michigan, USA

Ken Grattan

London, UK

Roger Howe

Stanford, California, USA

Koji Ikuta

Aichi, Japan 
Volume 280

Pages 1-572 (1 September 2018)
间 Download PDFs
政ort
Expand all article previews

1. Full text access

Editorial Board

Page ii

잔) Download PDF

Research article @ Full text access

Antistatic and dielectric properties of one-dimensional $\mathrm{Al}^{2+}: \mathrm{Nd}_{2} \mathrm{O}_{3}$ nanowire doped

polyaniline nanocomposites for electronic application

Aashis S. Roy

Pages 1-7

Download PDF Article preview $\vee$

$\square$ Research article • Full text access

Epitaxial graphene thermistor for cryogenic temperatures

Sirrı Batuhan Kalkan, Serap Yiğen, Cem Çelebi

Pages 8-13

$\square$ Research article • Full text access

Accurate measurement of high-frequency blast waves through dynamic compensation of miniature piezoelectric pressure sensors

Fan Yang, Deren Kong, Lin Kong

Pages 14-23

榔 Download PDF Article preview $\vee$

$\square$ Research article • Full text access

Relative humidity sensor based on small up-tapered photonic crystal fiber Mach-Zehnder interferometer

Rui-jie Tong, Yong Zhao, Mao-qing Chen, Yun Peng

Pages 24-30

뭅 Download PDF Article preview $\vee$

$\square$ Research article Full text access

Synthesis, characterization and application of magnetic carbon nanotubes for the simultaneous extraction and high performance liquid chromatographic determination of codeine and morphine in human urine, blood serum, opium and tablet samples Maryam Dehghani Soltani, Mohammad Ali Taher, Mansoureh Behzadi, Hamid Fazelirad Pages 31-37

闯 Download PDF Article preview $\checkmark$

$\square$ Research article • Open access

Thin film piezoelectric acoustic transducer for fully implantable cochlear implants Bedirhan lik, Aziz Koyuncuoğlu, Ozlem Sardan-Sukas, Haluk Külah Pages 38-46

$\square$ Research article • Full text access

A low-cost portable spherical directional anemometer for fixed points measurement A. Leoni, V. Stornelli, L. Pantoli

Pages 543-551

间 Download PDF Article preview $\vee$

$\square$ Research article Full text access

Liquid level sensor using two fiber bundles

Samian, A.H. Zaidan, Sujito, M. Yasin, ... Supadi

Pages 552-558

Download PDF Article preview $\checkmark$

$\square$ Research article • Full text access

An efficient signal conditioning circuit to piecewise linearizing the response characteristic of highly nonlinear sensors

Durga Nand Mahaseth, Lokesh Kumar, Tarikul Islam

Pages 559-572

Download PDF Article preview $\checkmark$ 


\section{Sensors and Actuators, A: Physical}

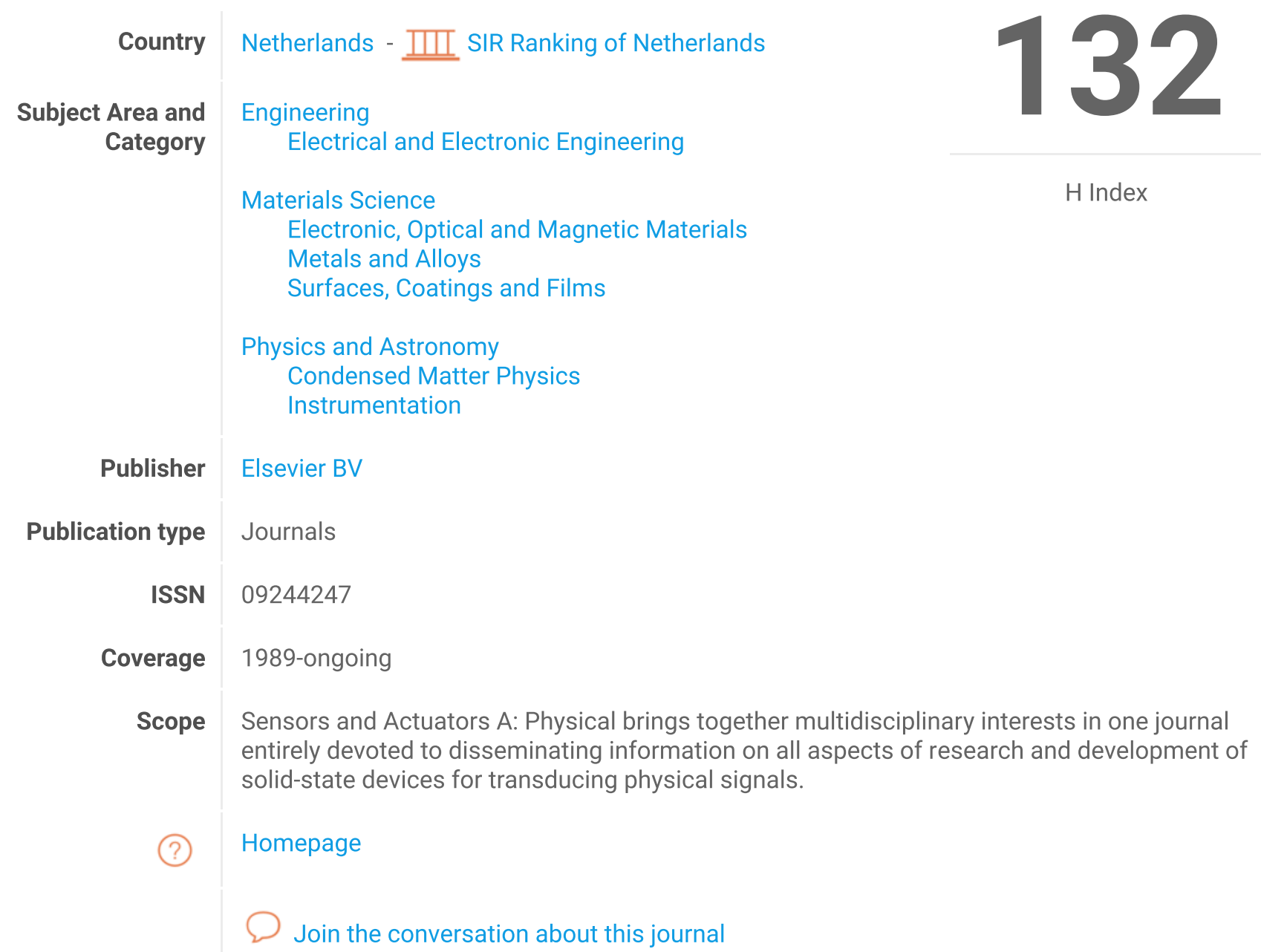
entirely devoted to disseminating information on all aspects of research and development of solid-state devices for transducing physical signals.

Homepage

Join the conversation about this journal

\section{Quartiles}

Condensed Matter Physics

Electrical and Electronic Engineering Electronic, Optical and Magnetic Materials Instrumentation Metals and Alloys Surfaces, Coatings and Films

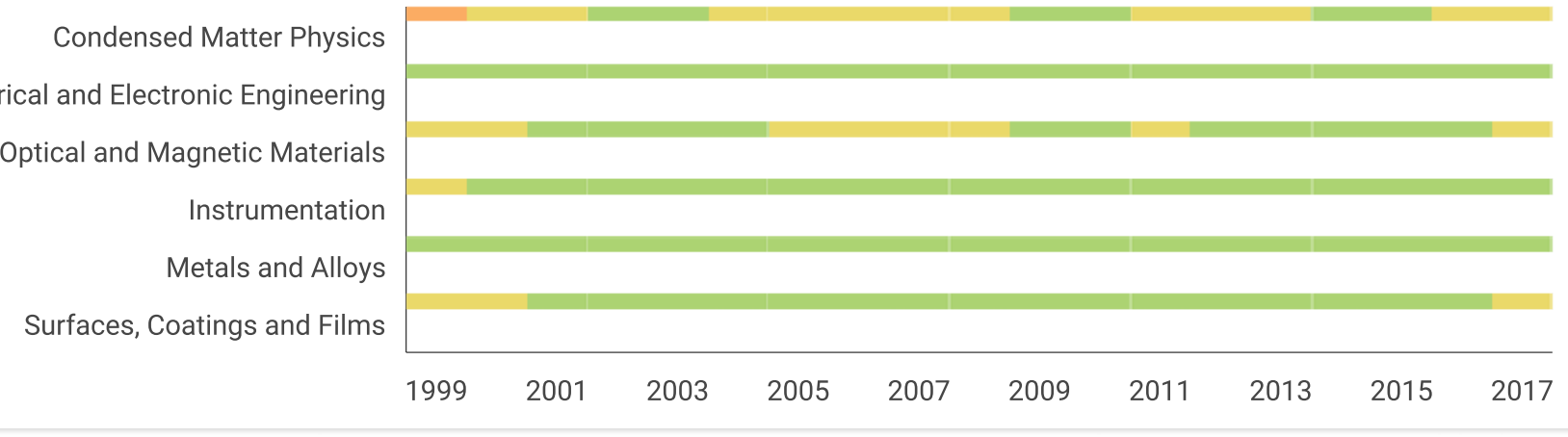




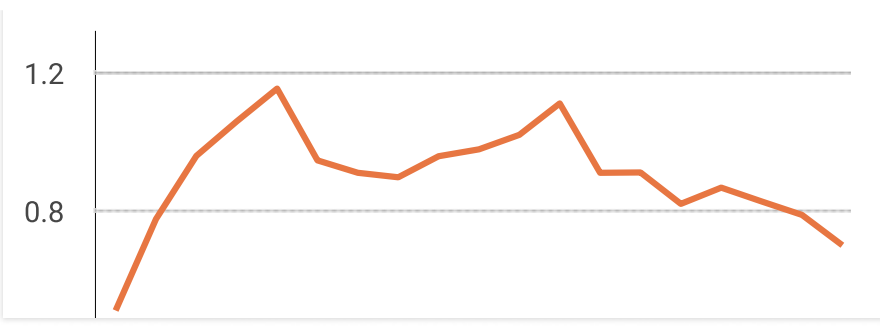

Total Cites Self-Cites

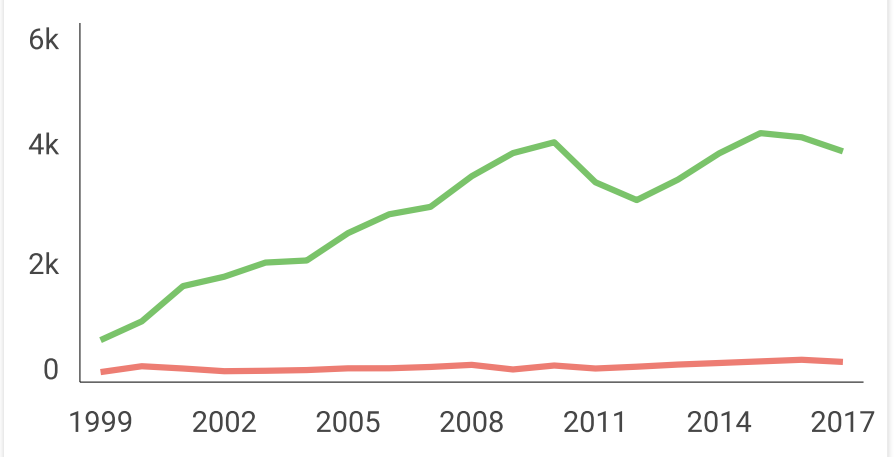

External Cites per Doc Cites per Doc

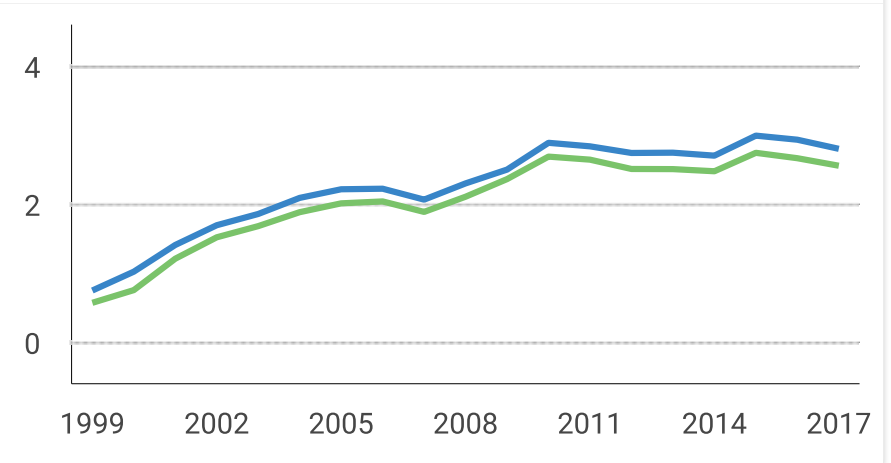

Citable documents Non-citable documents $\quad+$

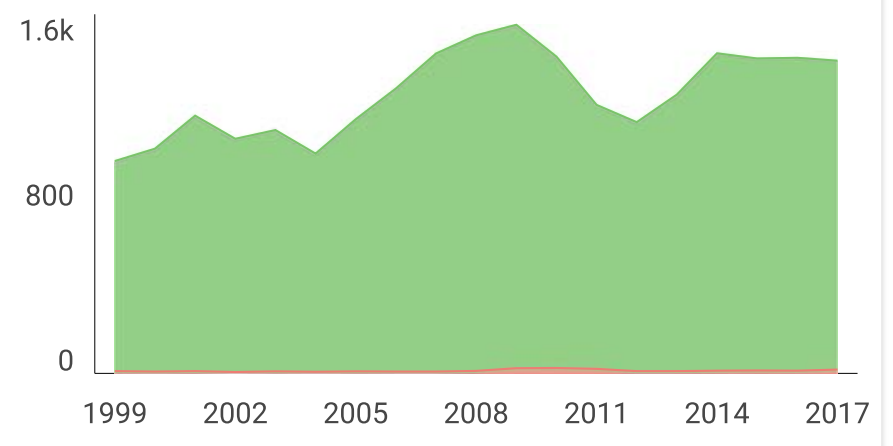

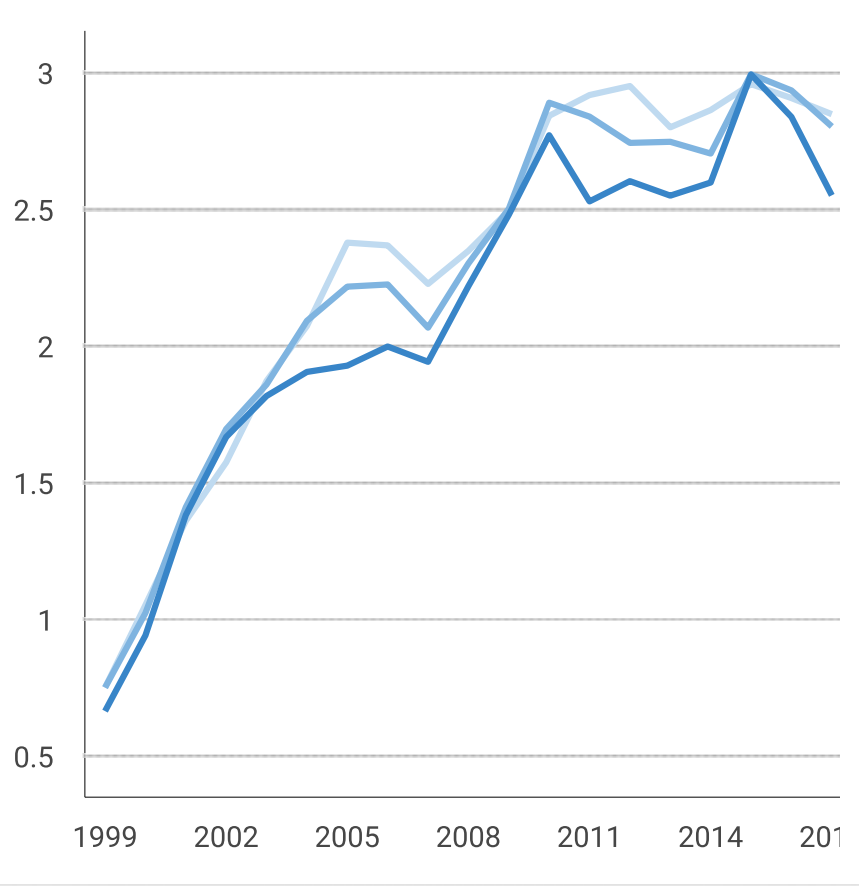

$\%$ International Collaboration

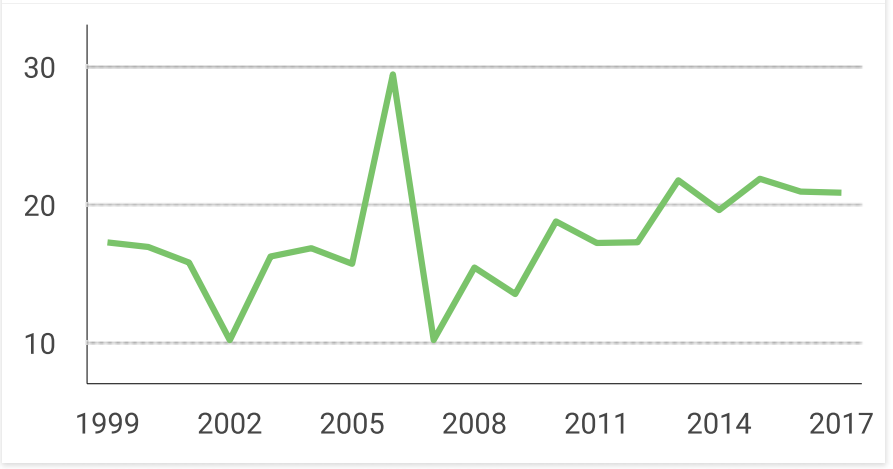

Cited documents Uncited documents $\quad+$

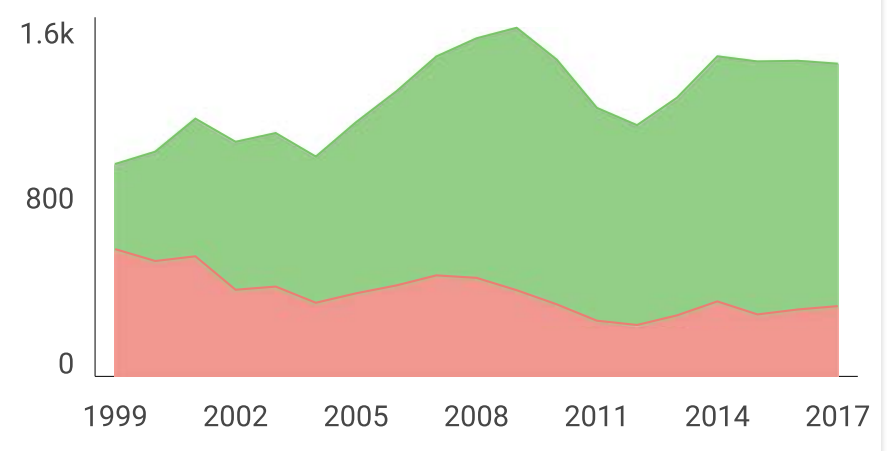

Sensors and Actuators, A: Physical

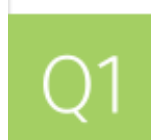

Electrical and

Electronic

Engineering

best quartile

SJR 2017

0.7

powered by scimagojr.com $\leftarrow$ Show this widget in your own website

Just copy the code below and paste within your html code:

$<$ a href="https://www.scimas 


\section{Leave a comment}

Name

\section{Email}

(will not be published)

Saya bukan robot

Submit

The users of Scimago Journal \& Country Rank have the possibility to dialogue through comments linked to a specific journal. The purpose is to have a forum in which general doubts about the processes of publication in the journal, experiences and other issues derived from the publication of papers are resolved. For topics on particular articles, maintain the dialogue through the usual channels with your editor.

Developed by:

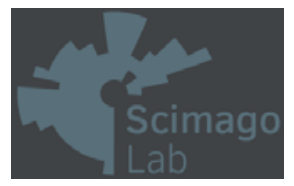

Follow us on @ScimagoJR
Powered by:

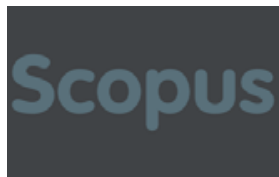

Scimago Lab, Copyright 2007-2018. Data Source: Scopus ${ }^{\circledR}$ 


\title{
Liquid level sensor using two fiber bundles
}

\author{
Samian $^{\mathrm{a}, *}$, A.H. Zaidan ${ }^{\mathrm{a}}$, Sujito $^{\mathrm{b}}$, M. Yasin ${ }^{\mathrm{a}}$, M. Pujiyati ${ }^{\mathrm{a}}$, Supadi $^{\mathrm{a}}$ \\ a Physics Department, Faculty of Science and Technology, Universitas Airlangga, Surabaya, Indonesia \\ ${ }^{\mathrm{b}}$ Physics Department, Faculty of Mathematics and Science, The State University of Malang, Malang, Indonesia
}

\section{A R T I C L E I N F O}

\section{Article history:}

Received 22 March 2018

Received in revised form 6 August 2018

Accepted 20 August 2018

Available online 22 August 2018

\section{Keywords:}

Liquid level sensor

Fiber bundled probe

Hydrostatic pressure

Front slope

Back slope

\begin{abstract}
A B S T R A C T
The two-tier detection of liquid level using two fiber bundles as sensor has been successfully demonstrated. Each fiber bundle is paired with a reflector displacement device (RDD) to detect liquid level in accordance with its detection area. Based on displacement sensor, the working principle of system is by utilizing hydrostatic pressure to shift the reflector attached to the membrane. Detection of liquid level is done through changes of reflected light intensity from the reflector that goes into each sensor probe. The results show that the sensor can be applied to the front slope or back slope area. Working area and resolution of sensors working on the front slope area are $0-130 \mathrm{~cm}$ and $1 \mathrm{~cm}$, meanwhile for the back slope area are $0-50 \mathrm{~cm}$ and $0.1 \mathrm{~cm}$.
\end{abstract}

(c) 2018 Elsevier B.V. All rights reserved.

\section{Introduction}

Optical devices based on optical fiber have been widely developed to detect liquid level. These devices including fiber Bragg gratings [1-3], photonic crystal fiber [4], fiber bundle [5,6], and fiber coupler $[7,10,11]$. The working principle of fiber Bragg grating and photonic crystal fiber is based on wavelength modulation in detecting liquid level. Meanwhile, the working principle of fiber optic, fiber coupler, and fiber bundle is based on the modulation of intensity.

Detection of liquid level based on intensity modulation has been done using fiber bundles coupled with transparent materials in the shape of conical [5] and prism [6] as sensor probes. The detection principle is based on changes in the reflected light intensity from the probe when interacting with the liquid. The change in the light intensity is then detected by fiber receiver of fiber bundle. A similar system has also been developed using fiber couplers as transmitters as well as receptors of reflected light in a prism [7]. In the application, the detection mechanism of these three systems is conducted indirectly, that is by moving the probe to search for liquid-air or vapor interface, meaning the probe is functioned as a switch. Another configuration is to polish the edge of an optical fiber and curved like a U-shaped letter. The change in the guided light intensity in optical fibers occurs when U-shaped interacts with the liquid. Along the optical fiber used, multiple U-shaped are placed

\footnotetext{
* Corresponding author.

E-mail address: samian@fst.unair.ac.id ( Samian).
}

over a range of distance. This means that altitude detection is not continuous and U-shaped functions as a multi-tier switch [8].

Based on displacement sensor using fiber coupler [9], direct and continuous liquid level detection has been performed using an output port of fiber coupler as a probe sensor [10]. The detection mechanism utilizes hydrostatic pressure to shift the reflecting reflector on the membrane. The reflector shift is observed from change in the reflected light intensity of the reflector entering an output port of the fiber coupler. The working area of the sensor increases to almost twice when two output ports of fiber coupler are used as probe sensor [11]. The detection mechanism is performed by two probe sensors in stages according to the working area.

Using the same method with the use of two outputs port of fiber coupler in detecting liquid level, in this paper, the use of two fiber bundles as probe sensors to detect liquid level will be demonstrated. Experimental results show that the sensor can be applied to two different areas (front slope and back slope area) with different characteristics. Compared to the use of two output ports of fiber coupler, the sensor range and work area are increased for application in the front slope area. For applications in the back slope area, a sensor with better resolution is obtained.

\section{Sensors design and operating principle}

The design of liquid level sensor using two fiber bundles (twotier sensor) is shown in Fig. 1(a). Two lasers used as a light source for transmitter fiber (TF) on each fiber bundle. Receiver fiber (RF) of the both fiber bundles that serves as light receiver connected directly 


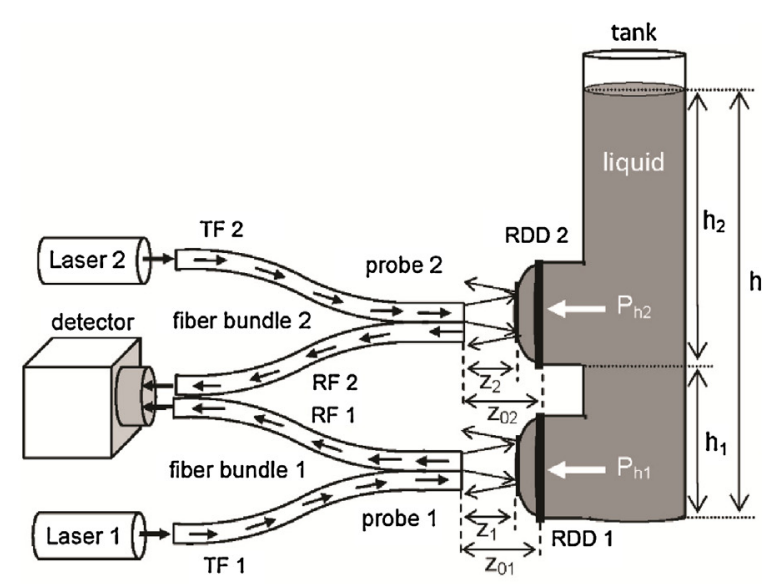

(a)

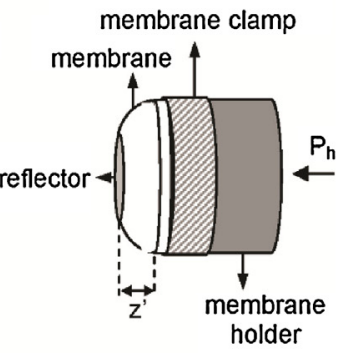

(b)

Fig. 1. (a) Design of two-tier sensor and (b) RDD.

to an optical detector. There are two reflector displacement device (RDD) on the tank wall. RDD consists of reflector (plate) which are glued on membrane as shown in Fig. 1(b). Reflector on RDD will shift $(z)$ when hydrostatic pressure $\left(P_{h}\right)$ changes due to changes in the liquid level $(h)$. Sensor 1 is built from probe 1 coupled with RDD 1 face-to-face and placed in the bottom of the tank. Meanwhile, sensor 2 is built from Probe 2 coupled with RDD 2 and placed in the level of $h_{1}$ above sensor 1 position. The distance between the probe and RDD reflector on sensor 1 and sensor 2 when tank in a state of empty each denoted with $z_{01}$ and $z_{02}$.

The working principle of two-tier sensor is as follow, sensor 1 detects the liquid level in the $h_{1}$ area and sensor 2 detect the liquid level in the $h_{2}$ area. Sensor 1 detects liquid level through the displacement of the RDD 1 reflector $\left(z_{1}\right)$ due to the change in liquid level in the $h_{1}$ area. The shift of RDD 1 reflector will result in a change in the reflected light intensity from the reflector entering FR 1 and can be read through the optical detector's output voltage value $(V)$. In the same way, sensor 2 works to detect the liquid level in the $h_{2}$ area. The shift in RDD 1 reflector is limited by using the barrier so that when the water level exceeds $h_{1}$, the reflector does not shift. That is, when liquid level exceeds $h_{1}$, the light intensity entering FR1 will be constant. On the other hand, when the liquid level does not go beyond $h_{1}$, the RRD 2 reflector will not shift as there is no change in hydrostatic pressure resulting in the intensity of light entering FR 2 is constant. Thus, the detection of liquid level from the bottom of the tank to the height of $h$ is performed alternately by sensor 1 and sensor 2 . If the level of RDD 2 is lower than $h_{1}$, then there is an area where liquid level is detected simultaneously by sensor 1 and sensor 2 .

\section{Experiment, result and discussion}

The experimental schematic diagram is shown in Fig. 2. The experimental set-up consists of two semiconductor lasers (with $630 \mathrm{~nm}$ wavelength and $10 \mathrm{~mW}$ of power output), silicon photodetector (PDA 100), two fiber bundles (type a pair bundled probe of plastic material with diameter of $1 \mathrm{~mm}$ and length of $2 \mathrm{~m}$ ) serves as a sensor probe (a plastic barrier was given to the end of one of sensor probes to resist reflector shifts), voltmeter (digital multimeter), xyz translation stage was used to shift sensor probe, manual water pump used to pump water into the tank, cylindrical scaled water tank which is made of glass (with diameter of $6 \mathrm{~cm}$ and length of $200 \mathrm{~cm}$ ), and two reflector displacement devices (RDD 1 and RDD 2 ). In the bottom of the water tank, there are a faucet used to remove the liquid. Both of RDDs used in this experiment consist of reflector which is made of aluminum (with diameter of $10 \mathrm{~mm}$ and thickness of $0.20 \mathrm{~mm}$ ), a membrane (nitrile polymer) with thickness of 0.08 (the elastic modulus is unknown), and cylindrical membrane holder which is made of brass with outer and inner diameter of $18 \mathrm{~mm}$ and $15 \mathrm{~mm}$. Reflector is attached to membrane using epoxy glue and membrane itself behaves like a spring. In this experiment, the liquid used is water.

The first experiment is to characterize shift of probe 1 against reflector RDD 1. Data retrieval was conducted by placing probe 1 in the middle and coinciding with the RDD 1 at the bottom of the tank as shown in Fig. 2. In this process, the tank is empty and the pair of probe 2 and RDD 2 is not installed yet. The recording of the detector's output voltage is carried out each probe 1 is shifted backward by $100 \mu \mathrm{m}$. xyz translation stage was used to shift the probe. The probe was shifted until detector's output voltage does not change significantly. The data were collected three times. The same procedure was conducted for the pair of probe 2 and RDD 2.

The results of first experiment are shown in Fig. 3. The characterization results show that the two reflectors are relatively identical. The difference in the value of peak voltage occurs because the handmade RDD is not identical.

The second experiment was carried out to find out the character of the liquid level sensor using a probe (one-tier sensor) for emptying and filling of the tank. The experiment was performed by placing sensor 1 (pair of probe 1 and RDD 1 ) on the hole at the bottom of the tank. Meanwhile, the second hole located above the first hole at the bottom of the tank is closed and sensor 2 is not activated. After sensor 1 is installed, the tank is filled with water as high as $150 \mathrm{~cm}$ and placing the probe 1 coincided with the RDD reflector 1. The maximum level of $150 \mathrm{~cm}$ is selected taking into account the maximum capability of the RDD membrane in resisting the water pressure. The sensor characterization for emptying the tank is carried out by record the optical detector output voltage when the water level is lowered by $1 \mathrm{~cm}$. After the tank is empty, characterization is performed for the tank filling process. The process is done by filling the tank with water using the pump and record the optical detector output voltage when the water level is raised by $1 \mathrm{~cm}$. The recording is performed until the maximum level of water in the tank is the same as during the emptying process. Data collection for tank filling and emptying process is done three times. In the second experiment, we also measured the distance between probe 1 and reflector RDD 1 when thank is empty $\left(z_{01}\right)$. The same procedure is performed for sensor 2 (pair of probes 2 - RDD 2 ).

The second experimental results are shown through the relation between the detector's output voltage $(V)$ and liquid level $(h)$ 


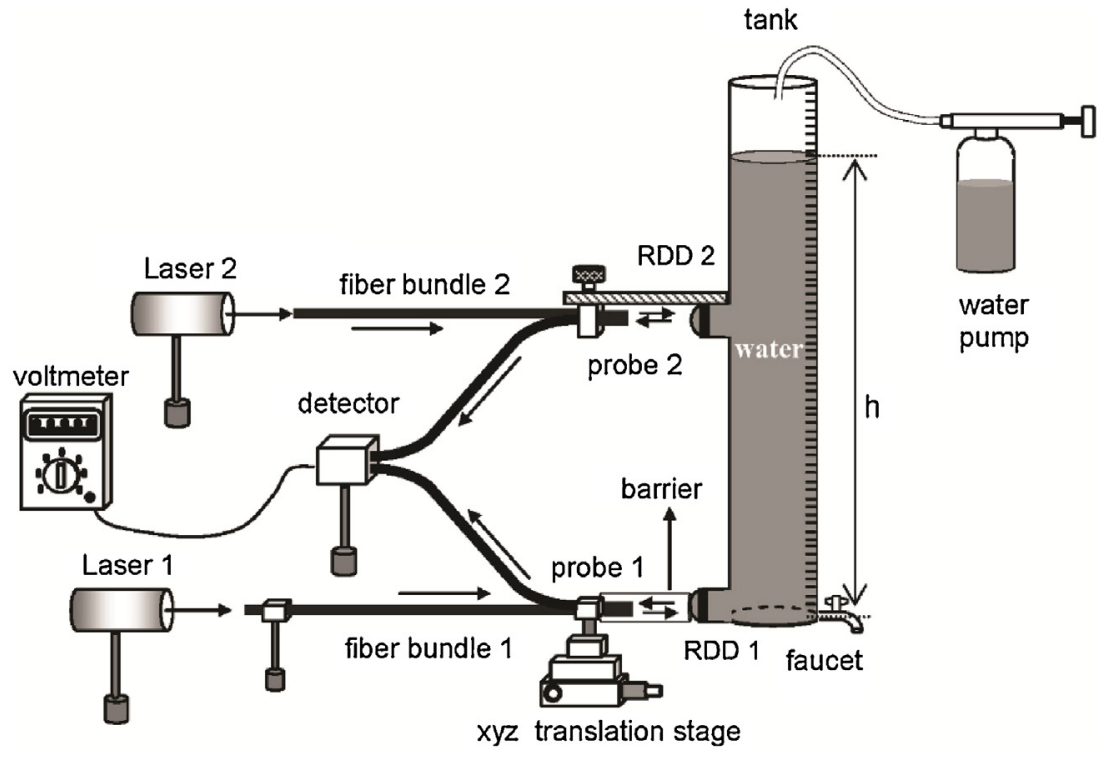

Fig. 2. Experimental set-up of two-tier sensor.

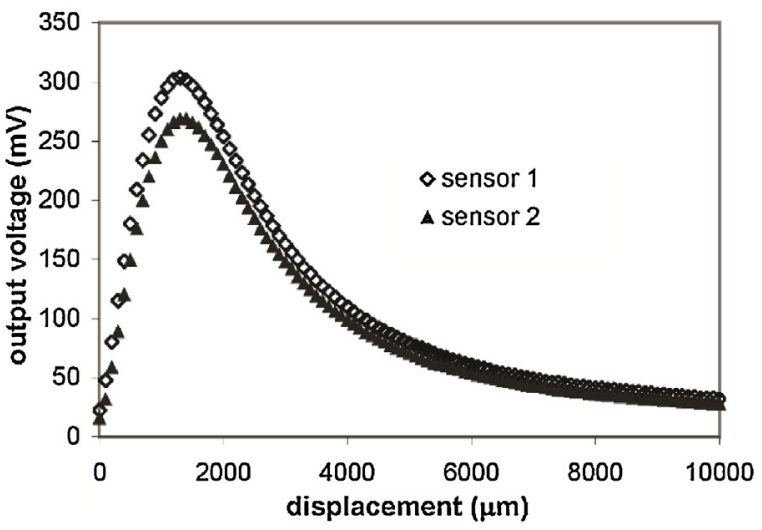

Fig. 3. Characterization results of probe shift against RDD reflector.

Table 1

The liquid level range that produce front slope and back slope areas.

\begin{tabular}{llllll}
\hline Area & \multicolumn{2}{l}{ Liquid level range $(\mathrm{cm})$} & & \\
\cline { 2 - 3 } & \multicolumn{2}{l}{ Sensor 1} & & & Sensor 2 \\
\cline { 2 - 3 } \cline { 5 - 6 } & emptying & filling & & emptying & filling \\
\hline Front slope & $0-120$ & $0-130$ & & $0-121$ & $0-132$ \\
Back slope & $120-150$ & $130-150$ & & $121-150$ & $132-150$ \\
\hline
\end{tabular}

graph in Fig. 4 with the largest measurement error values are $0.9 \mathrm{mV}$ $(0.7 \%)$ and $1 \mathrm{mV}(0.7 \%)$ for sensor 1 and sensor 2 . The $z_{01}$ and $z_{02}$ values are of the same magnitude of $7.7 \mathrm{~mm}$. As in previous studies $[10,11]$, the use of membranes as a sensor component causes the sensor output characteristics to produce hysteresis. The nature of the membrane relaxation after the pressure is the cause of the hysteresis. From Fig. 4, it appears that the dynamic range of sensor has two slopes, the front slope and the back slope in the liquid level range as shown in Table 1.

The presence of front slopes and back slopes in a dynamic range sensor causes the same output voltage value for two different points of liquid level. Therefore, it must be separated between the use of front slope and back slope area. The use of each of these areas can be done by limiting the maximum liquid level range of the detected liquid. The maximum liquid level range detected using
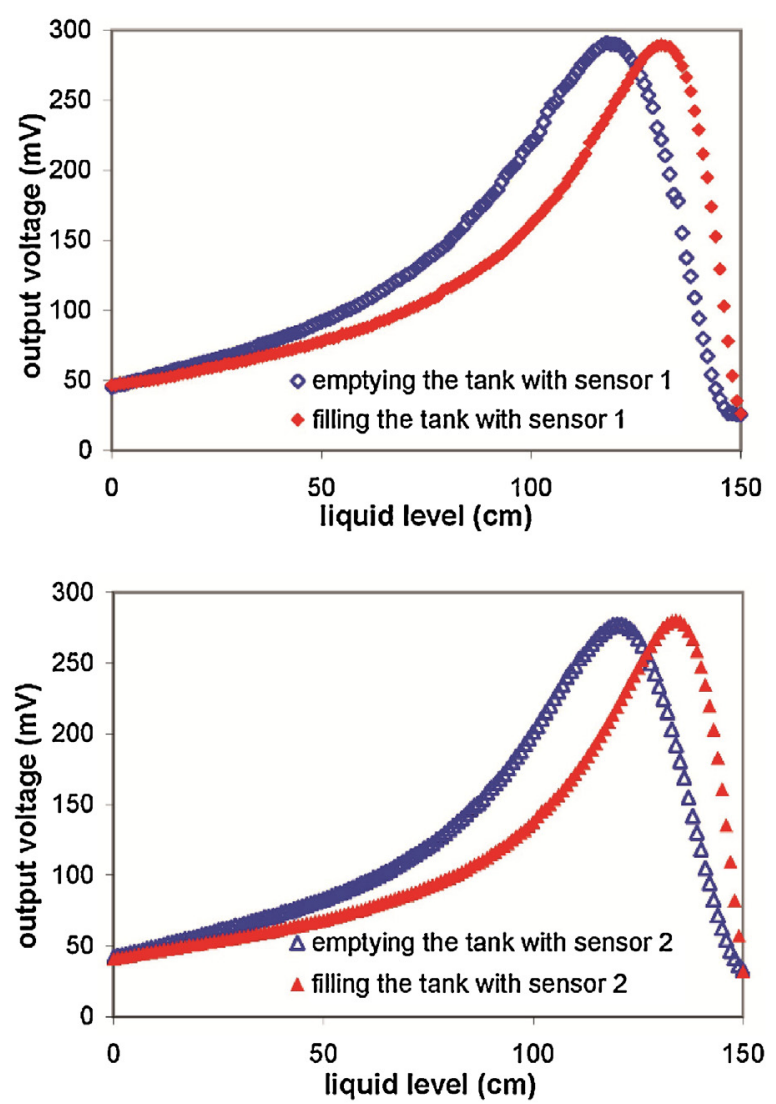

Fig. 4. Dynamic range of one-tier sensor for (a) sensor 1 and (b) sensor 2.

the front slope area is as shown in Table 1 with $z_{01}$ and $z_{02}$ values of $7.7 \mathrm{~mm}$. For the back slope area, the maximum liquid level range is the same as front slope but with different $z_{01}$ and $z_{02}$ values. To determine the sensor range that is expected to produce the back slope area only a third experiment is done. In this experiment, the maximum liquid level detected about $30 \mathrm{~cm}$ starts from level of $0 \mathrm{~cm}$. At the maximum of the liquid level, the sensor probe is placed close to the RDD reflector. Characterization is performed for emptying and filling of the tank for sensors 1 and sensor 2 such as the 


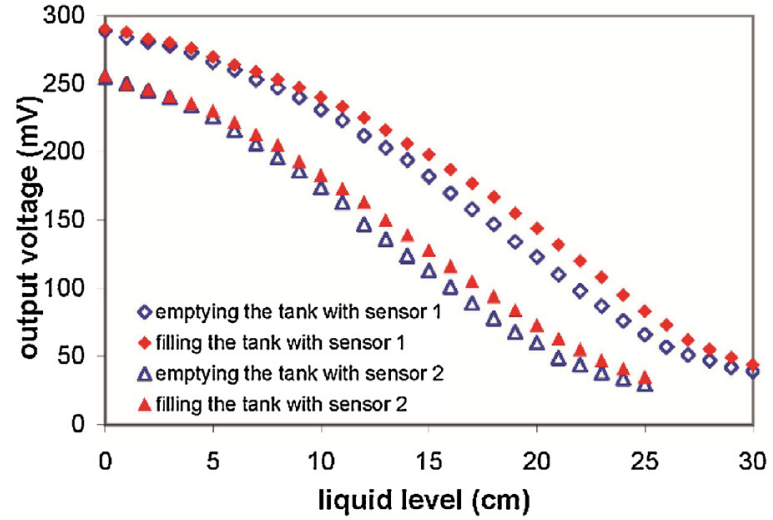

Fig. 5. Result of characterization of liquid level sensor which only produce back slope area.

previous process. Fig. 5 shows the mean values for the third experimental results with the largest measurement error being equal to $0.7 \mathrm{mV}(0.6 \%)$ for sensor 1 and sensor 2 . The measured $z_{01}$ and $z_{02}$ values of $1.44 \mathrm{~mm}$ and $1.37 \mathrm{~mm}$ respectively for sensor 1 and sensor 2 . For that, we conducted a third experiment, the characterization of sensor height for the area that was supposed to produce the back slope area only. In this experiment, the maximum liquid height detected about $30 \mathrm{~cm}$ starts from a height of $0 \mathrm{~cm}$. At the maximum height of the liquid, the sensor probe is placed close to the RDD reflector. Characterization is performed for the discharge and filling of the tank for sensors 1 and sensor 2 such as the previous process. The third experimental result, the average value shown by the graph in Fig. 5 with the largest measurement error is equal to $0.7 \mathrm{mV}(0.6 \%)$ for sensor 1 and sensor 2 . The measured $z_{01}$ and $z_{02}$ values are $1.44 \mathrm{~mm}$ and $1.37 \mathrm{~mm}$ respectively for the sensor 1 and sensor 2 .

The hysteresis of the third experiment differs from the second experiment for the back slope area. If the hysteresis output $(\mathrm{OH})$ parameter is used, i.e. half of the difference in the detector's output voltage at the emptying and filling process for the same liquid level as the differentiator, the maximum output values of hysteresis $(\mathrm{MOH})$ are $11 \mathrm{mV}$ and $8 \mathrm{mV}$ for sensor 1 and sensor 2 . For the second experimental back slope area, measured $\mathrm{MOH}$ values for sensor 1 and sensor 2 are $67.5 \mathrm{mV}$ and $65 \mathrm{mV}$ respectively. The difference in $\mathrm{MOH}$ values in the second and third experiments for the back slope area shows that $\mathrm{OH}$ is influenced by the maximum hydrostatic pressure experienced by the membrane.

The front slope area of the sensor uses the data taken from the graph in Fig. 4. While the back slope area of the sensor uses the data taken from the graph in Fig. 5. Sensor range for the front slope area is taken from a level of $0 \mathrm{~cm}$ to the liquid level that produces peak voltage. The working area of the sensor (linear region) for the use of the front slope and back slope area is shown by graph in Figs. 6 and 7. The Detector's output voltage $(V)$ is linear to liquid level $(h)$ with linearity more than $99 \%$ for the front slope and back slope area. The value of the linear region slope is the sensitivity value of the sensor.

The fourth experiment is the sensor stability test. The sensor stability test is performed by measuring the output voltage of the detector within a span of $30 \mathrm{~s}$ for $720 \mathrm{~s}$. The stability test is carried out in the linear region which is divided into six points of liquid level for the front slope area and four points for the back slope area. The result of the sensor stability test is the standard deviation value $(\Delta V)$ for the front slope area and the back slope of sensor 1 and sensor 2. For the front slope area, the largest $\Delta V$ for sensor 1 and sensor 2 are the same value of $0.7 \mathrm{mV}$. While for the back slope area, the largest value of $\Delta V$ are $0.6 \mathrm{mV}$ and $0.7 \mathrm{mV}$ respectively for
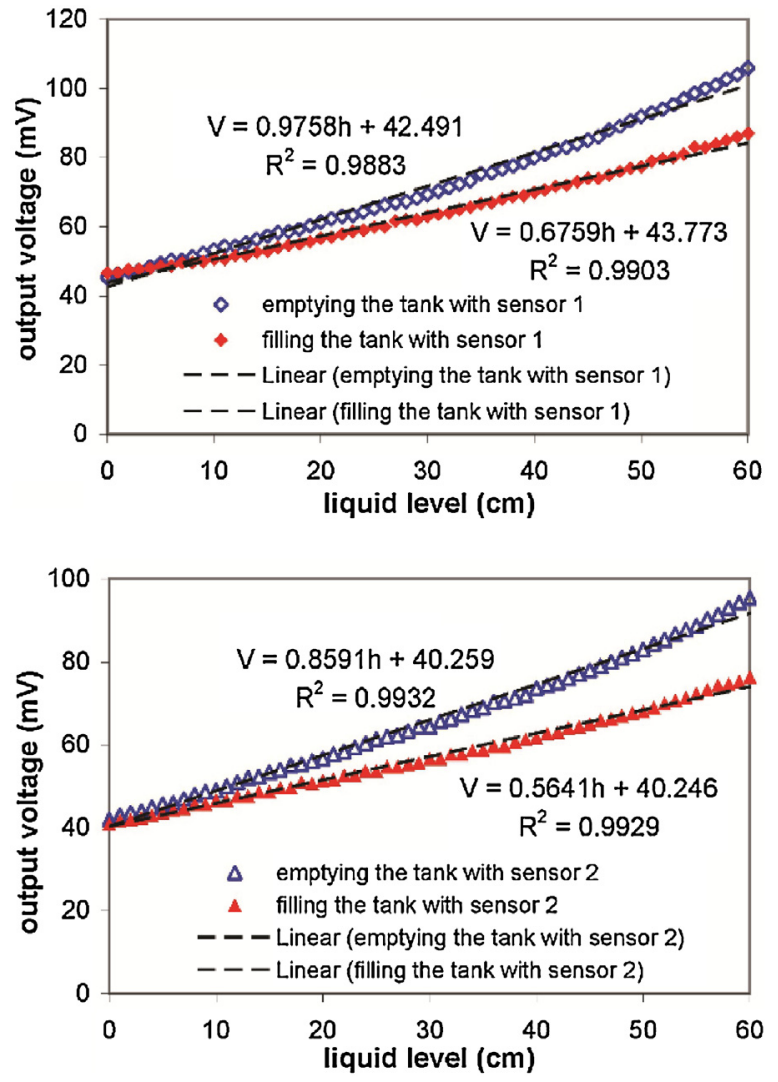

Fig. 6. The linear region of one-tier sensor using the front slope area for (a) sensors 1 and (b) sensor 2 .

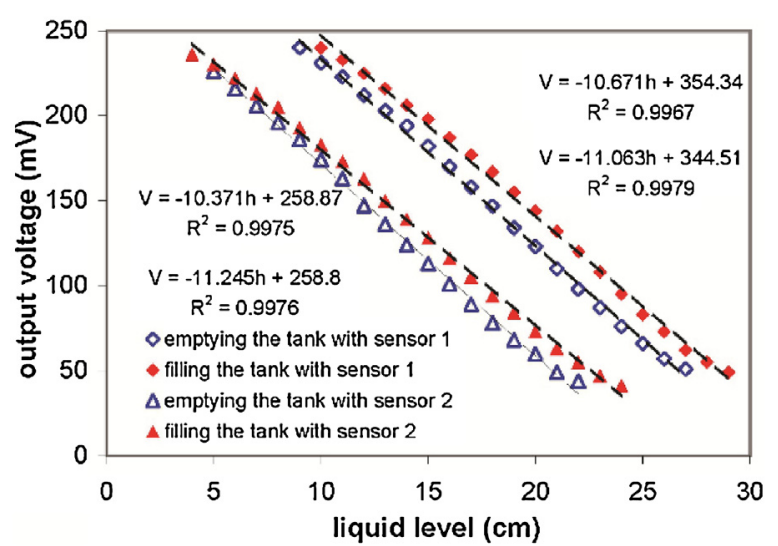

Fig. 7. The linear region of one-tier sensor using the back slope area for sensors 1 and sensor 2 .

sensor 1 and sensor 2 . From the largest $\Delta V$ value and sensor sensitivity value, the sensor resolution value can be obtained. From the data obtained, one-tier sensor characteristics are shown in Table 2. Table 2 shows that the use of the front slope area has a larger sensor range and linear region, but the resolution is no better than the use of the back slope area.

Sensitivity values for sensors 1 and sensor 2 using front slope area in the emptying and filling process are relatively similar. The same thing happens for the back slope area. It means that RDD 1 and RDD 2 have similar characteristics. Thus, the sensor 1 and sensor 2 can serve as components for two-tier sensor using both front slope and back slope area. The fifth experiment is performed to study liquid level detection by two-tier sensor using front slope and back slope area. This experiment aims to improve the sensor 
Table 2

Characteristics of one-tier sensor.

\begin{tabular}{|c|c|c|c|c|c|c|c|c|}
\hline \multirow[t]{3}{*}{ Parameter } & \multicolumn{4}{|c|}{ front slope area } & \multicolumn{4}{|c|}{ back slope area } \\
\hline & \multicolumn{2}{|l|}{ Sensor 1} & \multicolumn{2}{|l|}{ Sensor 2} & \multicolumn{2}{|l|}{ Sensor 1} & \multicolumn{2}{|l|}{ Sensor 2} \\
\hline & emptying & filling & emptying & filling & emptying & filling & emptying & filling \\
\hline Sensor range $(\mathrm{cm})$ & $0-120$ & $0-130$ & $0-121$ & $0-132$ & $0-30$ & $0-30$ & $0-25$ & $0-25$ \\
\hline Linear region $(\mathrm{cm})$ & $0-60$ & $0-60$ & $0-60$ & $0-60$ & $9-27$ & $10-29$ & $5-22$ & $4-24$ \\
\hline Sensitivity $(\mathrm{mV} / \mathrm{cm})$ & 0.98 & 0.68 & 0.86 & 0.56 & 11.1 & 10.7 & 11.3 & 10.4 \\
\hline Resolution (cm) & 1 & 1 & 1 & 1 & 0.1 & 0.1 & 0.1 & 0.1 \\
\hline
\end{tabular}
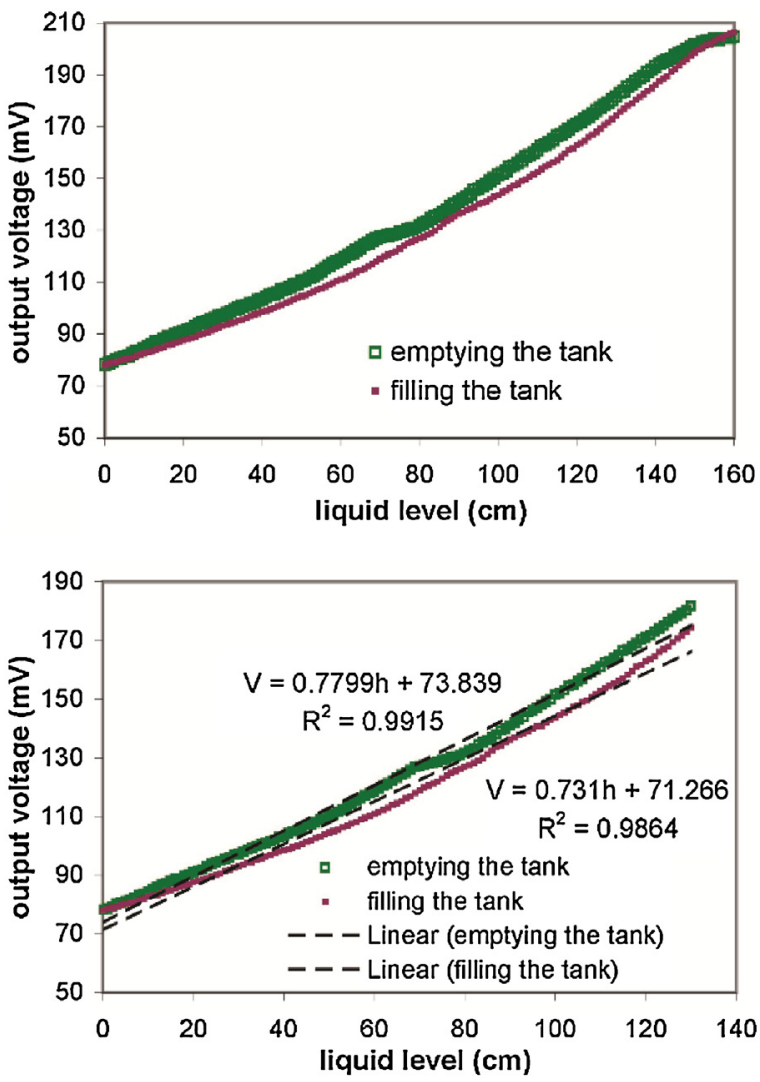

Fig. 8. (a) Sensor range and (b) linear region graph of liquid level detection by twotier sensor using front slope area.

working area. Experimental set-up for this experiment is shown in Fig. 2. To study the front slope area, sensor 1 is placed at the bottom of the tank and sensor 2 on top of it. The distance between sensor 1 and sensor $2\left(h_{1}\right)$ is $70 \mathrm{~cm}$ with $z_{01}$ and $z_{02}$ value made equal to $8 \mathrm{~mm}$. The maximum liquid level $(h)$ is $160 \mathrm{~cm}$. These parameters exceed the parameters of sensor 1 and sensor 2 which is selected to maximize the working area and sensor range. The reflector shift in RDD 1 is made constant by installing a barrier on probe 1 when the liquid level exceeds $70 \mathrm{~cm}$. To study the back slope area, Sensor 1 is placed at the base of the tank while the sensor 2 is placed $25 \mathrm{~cm}$ above the sensor $1\left(h_{1}\right)$. The positions of $z_{01}$ and $z_{02}$ are $1.44 \mathrm{~mm}$ and $1.37 \mathrm{~mm}$ and maximum liquid level $(h)$ is $50 \mathrm{~cm}$. Thus, if the liquid level is in the range of $25-30 \mathrm{~cm}$, then the detection is done simultaneously by sensor 1 and sensor 2 . The data collection for the emptying and filling process is done three times for both case of front slope and back slope area.

The result of the liquid level detection by two-tier sensor using the front slope area along with its linear region is shown in Fig. 8. The largest measurement error is $0.9 \mathrm{mV}(0.6 \%)$ with $\mathrm{MOH}$ value of $4.3 \mathrm{mV}$. The resulting linear region range is $0-130 \mathrm{~cm}$. Fig. 9 shows the result of the liquid level detection by two-tier sensor using the

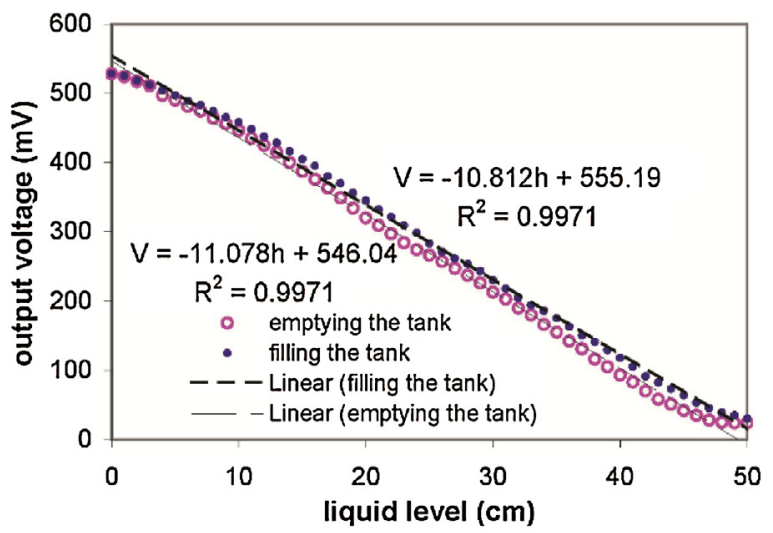

Fig. 9. Graph of liquid level detection by two-tier sensor using back slope area along with linear region.

Table 3

Characteristics of two-tier sensor using front slope and back slope area.

\begin{tabular}{llllll}
\hline \multirow{2}{*}{ Parameter } & \multicolumn{2}{l}{ Using front slope area } & & \multicolumn{2}{c}{ Using back slope area } \\
\cline { 2 - 3 } & emptying & filling & & emptying & filling \\
\hline Sensor range $(\mathrm{cm})$ & $0-160$ & $0-160$ & & $0-50$ & $0-50$ \\
Linear region $(\mathrm{cm})$ & $0-130$ & $0-130$ & & $0-50$ & $0-50$ \\
Sensitivity $(\mathrm{mV} / \mathrm{cm})$ & 0.78 & 0.73 & & 11.1 & 10.8 \\
Resolution $(\mathrm{cm})$ & 1 & 1 & & 0.1 & 0.1 \\
\hline
\end{tabular}

back slope area along with its linear region. The largest measurement error is $0.7 \mathrm{mV}(0.5 \%)$ and $\mathrm{MOH}$ value is $12.5 \mathrm{mV}$. The resulting linear region is the same as the sensor range. The value of the linear slope in Figs. 8 and 9, is the sensitivity value of each sensor.

The sixth experiment is a two-tier sensor stability test. the procedure is the same as the one-tier sensor stability test. The two-tier sensor stability test results using either the front slope or back slope area are shown in Fig. 10. From the sensor stability test, $\Delta V$ for the two-tier sensor using the front slope and back slope areas are $0.7 \mathrm{mV}$ and $1.1 \mathrm{mV}$. From the value of $\Delta \mathrm{V}$ and the sensitivity of the sensor, the sensor resolution can be obtained.

From the data obtained, the characteristics of the two-tier sensor using front slope and back slope area are summarized in Table 3. Data in Tables 2 and 3 indicate that the working area range of twotier sensor using either front slope or back slope area increased more than twice working area range of one-tier sensor. For a twotier sensor, the working area on the front slope area is 2.6 times the value of the sensor working area using the back slope area. On the other hand, the two-tier sensor using the back slope area has a resolution value 10 times better than using the front slope area.

Comparison of liquid-sensor performance using fiber optic (FBG, PCF, fiber coupler, and fiber bundle) with direct detection mechanism, is shown in Table 4. From the data presented, it is known that the proposed sensor has an advantage in the working area (linear region) for front slope area and resolution for back slope area. The membrane (nitrile polymer) as the RDD component in this experiment has also been used to detect gasoline level $[10,11]$. That is, 


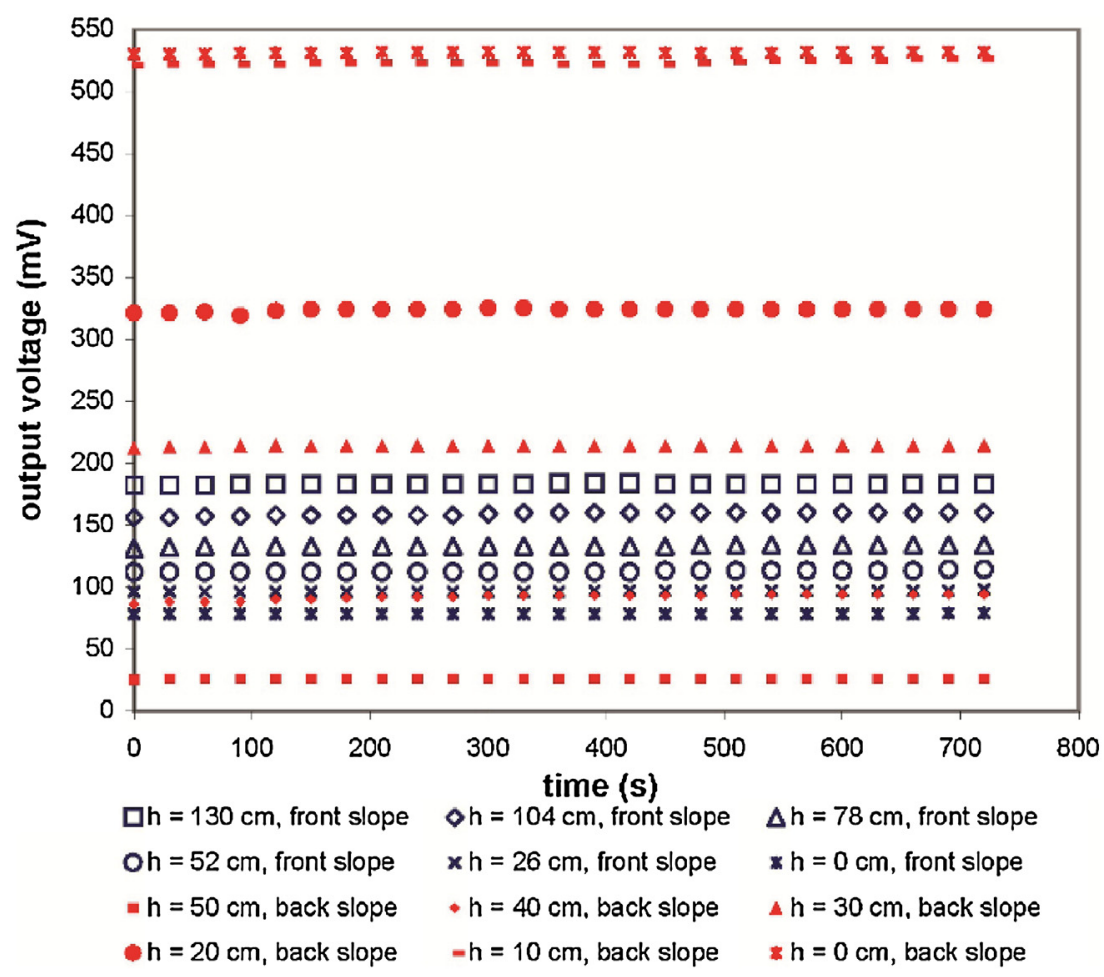

Fig. 10. Two-tier sensor stability test results using front slope and back slope area.

Table 4

The comparison of performance between optical level sensors.

\begin{tabular}{|c|c|c|c|c|c|}
\hline No. & method & $\begin{array}{l}\text { Sensor range } \\
(\mathrm{m})\end{array}$ & $\begin{array}{l}\text { Linear region } \\
\text { (m) }\end{array}$ & $\begin{array}{l}\text { Resolution } \\
(\mathrm{cm})\end{array}$ & Ref. \\
\hline 1. & Fiber Bragg Grating & 0.36 & 0.36 & 6 & [1] \\
\hline 2. & Tapered chirped fiber grating & 0.05 & 0.05 & - & {$[2]$} \\
\hline 3. & Long-period Fiber Bragg Grating & 1 & - & 10 & [3] \\
\hline 4. & Fiber interferometer using PCF & 0.05 & 0.05 & 0.5 & {$[4]$} \\
\hline 5. & Plastic optical fiber polished & 2.7 & - & 34 & [8] \\
\hline 6. & One output port fiber coupler & 1.8 & 0.4 & 0.6 & [10] \\
\hline 7. & Two output port fiber couplers & 1 & 0.7 & 0.4 & [11] \\
\hline \multirow[t]{3}{*}{8.} & One fiber bundle (our paper) & 1.25 & 0.6 & 1 & - \\
\hline & Front slope area & 0.3 & 0.18 & 0.1 & \\
\hline & Back slope area & & & & \\
\hline \multirow[t]{3}{*}{9.} & Two fiber bundles (our paper) & 1.6 & 1.3 & 1 & - \\
\hline & Front slope area & 0.5 & 0.5 & 0.1 & \\
\hline & Back slope area & & & & \\
\hline
\end{tabular}

our proposed sensor can be applied to detect other liquids other than the water. This may be done as long as the detected liquid is not detrimental to the elastic properties of the membrane. As is known, density of liquid will affect the magnitude of pressure produced at a certain level. With the sensor working mechanism based on the reflector displacement due to change in of the liquid level (hydrostatic pressure changes), thus the sensitivity of the sensor is influenced by the density of the detected liquid.

\section{Conclusions}

The liquid level can be detected in stages using two fiber bundles and two relatively identical RDDs. Each fiber bundle is paired with an RDD to form two sensors that work to detect liquid level in stages (two-tiers) according to the detection area. Detection of liquid level can use front slope or back slope area. The working area on the sensor using front slope area is twice more than the sensor using back slope area, while the resolution on the sensor using back slope area is ten times better than the sensor using the front slope area.

\section{References}

[1] Kyung-Rak Sohn, Joon-Hwan Shim, Liquid-level monitoring sensor systems using fiber Bragg grating embedded in cantilever, Sens. Actuators A Phys. 152 (2009) 248-251.

[2] D.O.N.G. XiaoWei, L.iu Wenkai, Z.hao Ruifeng, Liquid-level sensor based on tapered chirped fiber grating, Sci. China Ser. A-Math. Phys. Astron. Technol. Sci. 56 (2) (2013) 471-474.

[3] Jian-Neng Wang, Ching-Ying Luo, Long-period fiber grating sensors for the measurement of liquid level and fluid-flow velocity, Sensors 12 (2012) 4578-4593.

[4] Xinpu Zhang, Wei Peng, Zigeng Liu, Zhenfeng Gong, Fiber optic liquid level sensor based on integration of lever principle and optical interferometry, IEEE PhotonicsGlob. 6 (2) (2014), 6801108.

[5] Pekka Raatikainen, Ivan Kassamakov, Roumen Kakanakov, Mauri Luukkala, Fiber-optic liquid-level sensor, Sens. Actuators A Phys. 58 (1997) 93-97.

[6] Hossein Golnabi, Design and operation of a fiber optic sensor for liquid level detection, Opt. Lasers Eng. 41 (2004) 801-812.

[7] Chengning Yang, Shiping Chen, Guoguang Yang, Fiber optical liquid level sensor under cryogenic environment, Sens. Actuators A Phys. 94 (2001) 69-75.

[8] M. Lomer, J. Arrue, C. Jauregui, P. Aiestaran, J. Zubia, J.M. Lopez-Higuera, Lateral polishing of bends in plastic optical fibres applied to a multipoint liquid-level measurement sensor, Sens. Actuators A Phys. 137 (2007) 68-73. 
[9] Samian, Yono Hadi Pramono, Ali Yunus Rohedi, Febdian Rusydi, A.H. Zaidan, Theoretical and experimental study of fiber-optic displacement sensor using multimode fiber coupler, J. Optoelectron. Adv. Mater. - Rapid Commun. 3 (5) (2009) 411-414.

[10] Samian, G.Y.Y. Yhosep, A.H. Zaidan, Herlik Wibowo, Gasoline level sensor based on displacement sensor using fiber coupler, Measurement 58 (2014) 342-348.

[11] Samian, Y.G.Y. Yhuwana, A.H. Zaidan, Supadi, Sujito, Application of two-output port fiber coupler as gasoline level sensor, Measurement 85 (2016) 80-87.

\section{Biographies}

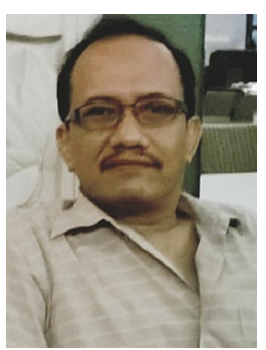

Samian received his Bachelor degree in Physics from Universitas Airlangga, Indonesia in 1996 and his Master degree from Institut Teknologi Sepuluh Nopember, Indonesia in 2008. He is now an Associate Professor at Photonics Lab., Universitas Airlangga, Indonesia. His research interests are in the area of fiber sensor.

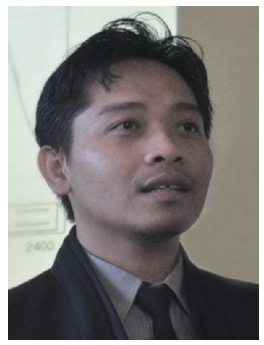

Andi Zaidan received both of the Bachelor and Master degree from Departement of Physics, Intitut Teknologi Bandung, Indonesia. He has pH.D. degree from UCTM Sofia, Bulgaria. Currently he is working as an Associated Professor in Physics Department, Universitas Airlangga, Indonesia. His current research involving applications of new materials in optoelectronics and photonics.

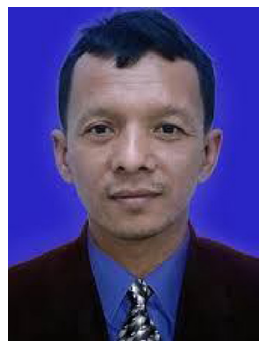

Sujito has completed Bachelor of Physical education from The State University of Malang in 1999 and Master Physics at Institut Teknologi Sepuluh Nopember Indonesia in 2008. His research interests are in the area of optoelectronics. His current position is as Lecturer and researcher at Physics Department, Faculty of Mathematics and Science, The State University of Malang, Indonesia.

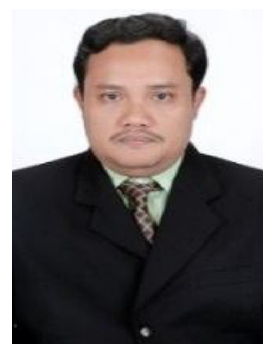

M. Yasin received his B. Sc. in 1990 at Airlangga University, and M.Sc. and pH.D degrees from Gadjah Mada University in 1999 and 2010, respectively. Currently, he is a professor at the Faculty of Science and Technology, Airlangga University, Surabaya, Indonesia. His research interests include fiber optic sensors and fiber laser.

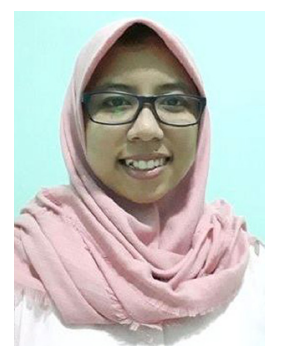

Minda Pujiati has worked in photonics Lab, Universitas Airlangga since 2015 and graduated from the Department of Physics, Universitas Airlangga in 2017. Her research interests are in the area of fiber sensor.

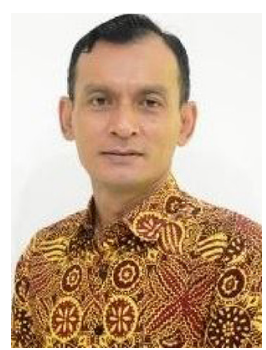

Supadi has completed Bachelor of Physics from Universitas Airlangga in 1997 and Master Physics at Institut Teknologi Sepuluh Nopember Indonesia in 2006. He is author of several physics books and a researcher in Department of Physics, Universitas Airlangga, Indonesia. His research interests are in the area of laser Spectroscopy. 